\title{
Integration of Interpretive Structural Modeling with Fuzzy Bayesian Network for Risk Assessment of Tunnel Collapse
}

\author{
Leping He $\mathbb{D}^{1},{ }^{1}$ Tao Tang, ${ }^{1}$ Qijun Hu, ${ }^{1}$ Qijie Cai, ${ }^{2}$ Zhijun Li, ${ }^{3}$ Shaowu Tang, \\ and Yichun Wang ${ }^{5}$ \\ ${ }^{1}$ School of Civil Engineering and Geomatic, Southwest Petroleum University, Chengdu 610500, China \\ ${ }^{2}$ School of Transportation and Logistics, Southwest Jiaotong University, Chengdu 611756, China \\ ${ }^{3}$ School of Civil Engineering, Southwest Jiaotong University, Chengdu 611756, China \\ ${ }^{4}$ The 2nd Department of China Railway Tunnel Group Co. Ltd, Langfang 065000, China \\ ${ }^{5}$ China Railway 23rd Bureau Group Co., Ltd, Chengdu 610075, China \\ Correspondence should be addressed to Leping He; 201231010028@swpu.edu.cn
}

Received 24 August 2021; Accepted 4 December 2021; Published 23 December 2021

Academic Editor: Min Ye

Copyright (C) 2021 Leping He et al. This is an open access article distributed under the Creative Commons Attribution License, which permits unrestricted use, distribution, and reproduction in any medium, provided the original work is properly cited.

\begin{abstract}
Frequent collapse accidents in tunnels are associated with many construction risk factors, and the interrelationship among these risk factors is complex and ambiguous. This study's aim is to clarify the relationship among risk factors to reduce the tunnel collapse risk. A multicriteria decision-making method is proposed by combining interpretive structural modeling (ISM) and fuzzy Bayesian network (FBN). ISM is used to determine the hierarchical relationships among risk factors. FBN quantitatively analyzes the strength of the interaction among risk factors and conducts risk analysis. The ISM-FBN method contains three steps: (1) drawing the ISM-directed graph; (2) obtaining the probability of the FBN nodes; and (3) using GeNle to implement risk analysis. The proposed method is also used to assess the collapse risk and detect the critical factors in the Canglongxia Tunnel, China. This method's tunnel collapse risk model can provide managers with clear risk information and better realize project management.
\end{abstract}

\section{Introduction}

In recent years, with the continuous increase in traffic demand and the shortage of land, the tunnel relies on shortening the road mileage, relieving ground transportation pressure, and improving city operation efficiency; the advantages of saving land and protecting the environment have been rapidly developed. According to relevant statistics, as of 2017, China had completed 30,981 operating tunnels with a total length of $31,021 \mathrm{~km}$ [1]. Under the background of tight land use and increased traffic volume, the amount of tunnel construction will be even more rapid in the future. However, during the tunnel's construction, the complex engineering-geological environment has intense uncertainty, leading to tunnel construction safety accidents. At present, common tunnel construction safety accidents include collapse, water and mud inrush, gas explosion, rock burst, large deformation, fire, etc. If these accidents are not adequately controlled, the project's construction progress will be affected, and severe injuries and property losses will be caused, which will cause a tremendous social impact. Among the 111 tunnel construction safety accidents counted from 2001 to 2016, tunnel collapse accidents accounted for about 56\% [1]; this type of accident had aroused widespread public concern and increased the sensitivity to the risk of tunnel collapse.

Tunnel construction collapse is affected by multiple aspects, including design, construction, geology, etc. In recent years, the multicriteria decision-making method, which integrates numerous risk factors, has been introduced to solve the risk assessment. Chen et al. [2] introduced a technique based on the T-S fuzzy fault tree to analyze the possibility of tunnel collapse. The multilevel fuzzy comprehensive decision-making method was used to evaluate the tunnel collapse risk [3]. Zhang et al. [4] proposed a technique of rough sets and advanced geological prediction 
to assess the collapse risk of the tunnel. Yuan et al. [5] selected eight main factors to construct a mountain tunnel landslide index system and used the catastrophe theory model to predict the possibility of Hongyansi Tunnel collapse. A dynamic risk assessment was carried out on a new attribute interval assessment model before and after the tunnel excavation [6]. Sun et al. [7] summarized the tunnel collapse factors from practical cases and proposed multistate fuzzy Bayesian networks. The procedure is as follows: the fault tree was used to describe the relationship among elements, and then the fault tree was mapped to the Bayesian network. The risk factors were obtained based on rough set conditional information entropy [8]. Xue et al. [9] proposed a fuzzy comprehensive evaluation model to predict the collapse risk of the Zhengwan Soft Rock Tunnel. These works make extraordinary contributions to reducing the risk of tunnel collapse. However, some of the tunnel collapse accident analysis approaches are linear $[2,7]$. Besides, little literature considered the interaction among the risk factors, which leads to a significant difference between the risk assessment result and the actual situation. The cause of the accident needs to be analyzed not only from the characteristics of the factors themselves but also from the relationship among the factors [10].

Some methods have been devoted to studying the interaction among accident factors, including System Theoretic Accident Modeling and Processes (STAMP) [11, 12], Functional Resonance Analysis Method (FRAM) [13], "2-4” model [14], Structural Equation Modeling (SEM) [15, 16], etc. STAMP, FRAM, and the " $2-4$ " model require finding out the interaction. However, the results are affected by the researchers' subjective influence. Meanwhile, the factors' complexity increases the consumption of brainpower and time. SEM needs a large number of questionnaires to support establishing the interaction. Interpretive structural modeling (ISM) $[17,18]$ can overcome the above limitations to a certain extent. However, only a few studies quantitatively studied the interaction among factors, while most studies were qualitative. The risk of tunnel collapse is uncertain, which is induced by many factors and their complex interactions. Therefore, it is necessary to propose a method to perform uncertainty reasoning and quantitatively describe the interactions.

Risk assessment is a reasoning process that integrates various uncertain risk factors. The standard uncertainty reasoning tools include Bayesian network (BN) [19, 20], C-F model [21], Dempster-Shafer (DS) evidence theory [22], etc. Among these tools, BN constantly updates the probability and reversing reasoning, which was widely used in risk assessment and management [23-29]. However, the implementation of $\mathrm{BN}$ requires numerous prior probability and conditional probability information. The uncertainty of risks in actual projects makes it difficult to obtain this information and determine an accurate and precise number. In recent years, the fuzzy Bayesian network (FBN) is proved to overcome the aforementioned limitations. A polymorphic FBN was proposed to analyze the subway station's bottomless foundation pit [30]. Ren et al. [31] applied FBN to find the causal relationship between the risk factors that cause marine operations accidents.
Mechri et al. [32] analyzed the uncertainty of security system performance with FBN and verified the accuracy of the results with the Monte Carlo method. Aliabadi et al. [33] employed FBN to find the critical accident factors to prevent the severe consequences of hydrogen leakage. There are many risk factors for existing tunnel collapse accidents, and the interrelationship among factors is complicated and vague. However, the current risk assessment methods lack considering the interaction among factors and quantifying their strength.

This study aims to propose a risk assessment method by combining the ISM and FBN. First, ISM determines the interaction among risk factors that affect tunnel collapse, layers the risk factors, and qualitatively analyzes the factor's importance. Then, the factor hierarchical structure model obtained by ISM is mapped to BN. Experts' opinions are processed through similarity aggregation method (SAM) to receive the prior probability and conditional probability of the FBN node. Finally, FBN quantitatively analyzes the strength of the interaction and conducts risk analysis.

The remainder of this paper is organized as follows. Section 2 briefly introduces the fundamental theories of the interpretation structure model, BN, and fuzzy set theory. Section 3 describes the specific implementation method of the interpretation structure model and FBN. In Section 4, the proposed method is used to analyze the risk of the case. In Section 5, the advantages, capacities, and limitations of the developed approach are discussed. In Section 6, the major conclusions are presented.

\section{Preliminaries}

This section mainly shows a preliminary introduction to important theoretical principles used in this paper. Interpretive structural modeling is used to identify relationships between factors and establish the directed graph of tunnel collapse risk. The Bayesian network model is used for probability reasoning. A priori probability of the essential element is obtained by fuzzy set theory.

2.1. Interpretive Structural Modeling (ISM). ISM, developed by John Warfield in 1973, aims to transform ambiguous thoughts and viewpoints into a clear hierarchical structure, which reveals the relationship between the internal elements of the system [34]. The implementation steps are as follows [35-38].

Step 1. Identify the critical factors of the system.

Step 2. Determine the relationship between factors and construct the relation matrix $\mathbf{M}_{0}$.

Step 3. Calculate the reachability matrix $\mathbf{M}_{1}$ according to the relation matrix $\mathbf{M}_{0}$.

Step 4. Reach the matrix level division and determine the factor level.

Step 5. Draw a directed graph. 
2.2. Bayesian Network (BN). BN is a powerful tool to express uncertain knowledge and reasoning, widely used in fault diagnosis and causal rationale [39]. It is a combination of graph theory and probability theory, which consists of a directed acyclic graph (DAG) and an associated joint probability distribution (JPD) [40]. The DAG is composed of nodes and directed arcs. The nodes represent the state of the attributes, and the directed arcs represent the relationship between the features. The arrow represents the child node, and the arrow tail represents the parent node. The BN's reasoning is expressed by the following equation:

$$
P\left(X_{j} \mid X_{i}\right)=\frac{P\left(X_{j}\right) \cdot P\left(X_{i} \mid X_{j}\right)}{P\left(X_{i}\right)},
$$

where $P\left(X_{i}\right)$ is the prior probability; $P\left(X_{i} \mid X_{j}\right)$ is the conditional probability, which indicates the condition of the occurrence of factor $X_{j}$ with the probability value of the occurrence of element $X_{i}$; and $P\left(X_{j} \mid X_{i}\right)$ is the posterior probability. is

For a group of variables $\left.X_{i} \in X=\left\{X_{1}, X_{2}, \ldots, X_{n}\right\}\right)$, the JPD

$$
P(X)=\prod_{i=1}^{n} P\left(X_{i} \mid p a\left(X_{i}\right)\right),
$$

where $p a\left(X_{i}\right)$ represents the parent node of $X_{i}$ in the BN structure.

A simple BN structure with three nodes is constructed to facilitate understanding, as shown in Figure 1. Node $X_{1}$ is the parent node of the BN structure graph $X_{2}$ and $X_{3} . X_{2}$ and $X_{3}$ are child nodes. $X_{1}$ has no parent node, called the root node. $X_{2}$ and $X_{3}$ have no child nodes, called leaf nodes. In the conditional probability table (CPT), 1 means that the event occurred and 0 means that the event did not happen.

2.3. Fuzzy Set Theory. If the data were insufficient, the probability of $\mathrm{BN}$ nodes would be challenging to obtain through parameter learning. Consulting experts are commonly used to obtain the prior probability and conditional probability of the nodes. Due to the uncertainty of risks in actual projects, it is tricky for experts to determine an accurate and precise number. Thus, fuzzy set theory is introduced. Triangular fuzzy numbers and trapezoidal fuzzy numbers are commonly used to deal with uncertain numbers. This paper uses triangular fuzzy numbers to describe the probability of nodes. It is defined as $T=\left(s_{1}, s_{2}, s_{3}\right)$, and its membership function graph is shown in Figure 2. The triangular membership function is

$$
\mu x= \begin{cases}0, & x \leq s_{1}, \\ \frac{x-s_{1}}{s_{2}-s_{1},} & s_{1}<x \leq s_{2}, \\ \frac{s_{3}-x}{s_{3}-s_{2}}, & s_{2}<x \leq s_{3}, \\ 0, & x>s_{3} .\end{cases}
$$

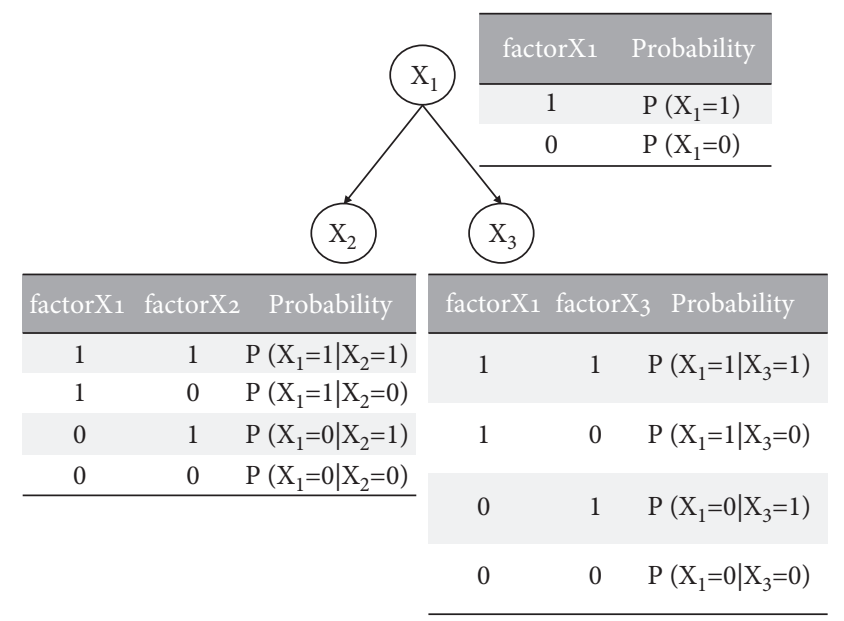

Figure 1: Bayesian network diagram.

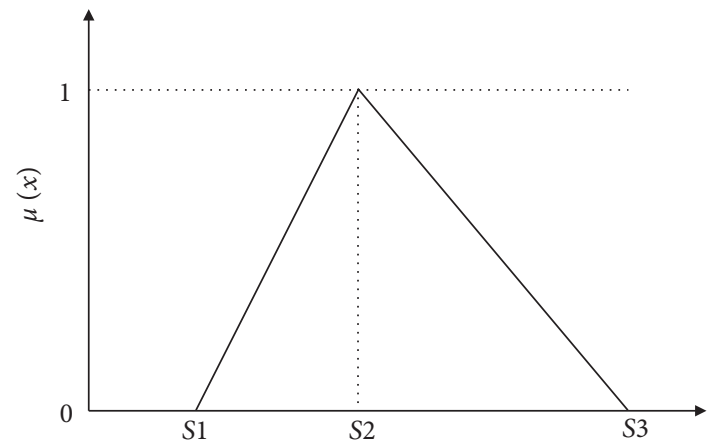

FIgURE 2: Triangular membership function.

\section{Methodology}

The ISM-FBN method is developed to improve the tunnel collapse risk assessment's accuracy and establish and quantify the interaction among the collapse factors. The workflow is shown in Figure 3, which includes three main parts: (i) drawing the ISM-directed graph; (ii) obtaining BN probability; and (iii) risk analysis.

3.1. Drawing the ISM-Directed Graph. The implementation of ISM is elaborated in five parts to determine ISM-directed graph of the tunnel collapse factors.

Step 6. Identification of collapse risk factors.

A total of 233 tunnel collapse accidents in 2000-2017 were counted to summarize the five aspects affecting tunnel collapse, i.e., geology, survey and design, construction, organizational management, and nature. Most factors in the five aspects were integrated to reduce the factors' number and the model's complexity (for more details, the readers are referred to the relevant literature $[5,7,41])$. Finally, we determined 17 factors that mainly affected the tunnel collapse, as listed in Table 1.

Geological Aspects. The unpredictability of geological conditions is the leading cause of tunnel collapse. 


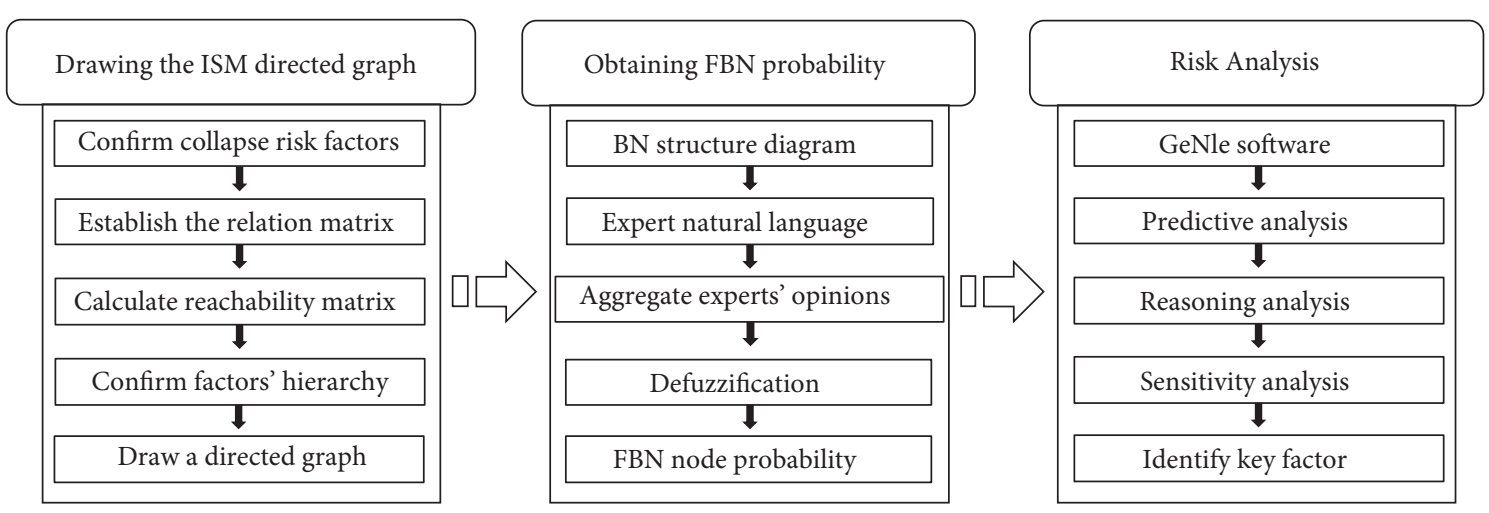

FIGURE 3: Workflow of tunnel collapse risk assessment based on ISM and FBN.

TABle 1: Tunnel collapse factors.

\begin{tabular}{|c|c|c|c|}
\hline Factor & Description & Statistics & Percentage \\
\hline$Y 1$ & Poor stability of surrounding rock & 187 & 22.94 \\
\hline$Y 2$ & Special poor geological conditions & 73 & 8.96 \\
\hline$Y 3$ & Severe bias & 26 & 3.19 \\
\hline$Y 4$ & Shallow buried & 32 & 3.93 \\
\hline Y5 & Mutation of geological conditions & 18 & 2.21 \\
\hline Y6 & Groundwater seepage & 107 & 13.13 \\
\hline$Y 7$ & Inaccurate geological survey & 36 & 4.42 \\
\hline Y8 & Unreasonable design & 14 & 1.72 \\
\hline$Y 9$ & Irregular construction & 59 & 7.24 \\
\hline$Y 10$ & Improper construction measures or poor quality & 27 & 3.31 \\
\hline$Y 11$ & Untimely support & 34 & 4.17 \\
\hline$Y 12$ & Insufficient support strength & 21 & 2.58 \\
\hline$Y 13$ & Excessive construction disturbance & 42 & 5.15 \\
\hline$Y 14$ & Low level of management awareness & 39 & 4.79 \\
\hline$Y 15$ & Failure of monitoring and measurement standards & 16 & 1.96 \\
\hline$Y 16$ & Inadequate advance geological forecast & 9 & 1.10 \\
\hline$Y 17$ & Atmospheric rainfall & 75 & 9.20 \\
\hline
\end{tabular}

According to 233 accidents, the probability of geological aspects' factors is $54.57 \%$ to cause the tunnel collapse. The geological characteristics include the strength of surrounding rock, the integrity of surrounding rocks, faults, fracture zones, karst caves, loess, expansive soil, bias angle, surrounding rock transition zone, shallow burial, groundwater, etc. Six main factors are integrated: poor stability of surrounding rock, special poor geology conditions, severe bias, mutation of geological conditions, shallow buried, and groundwater seepage.

Survey and Design Aspects. 233 cases involved 43 cases that were the survey and design aspects, which are accounted for $5.61 \%$. The survey and design aspects are specifically manifested in the rationality of parameter selection, the completeness of the data, the accuracy of the geological survey, etc. Two main factors are obtained through integration: unreasonable design and inaccurate geological survey.

Construction Aspects. The probability of tunnel collapse caused by construction aspects' factors is $22.85 \%$. They are manifested in unreasonable process arrangement, excessive footage, overexcavation, failure to construct as design, implementation of construction plans and organizational measures, improper construction methods and techniques, existence and implementation of drainage plan, construction quality problems, timeliness of support, the timeliness of the lining, the strength of the support, the construction machinery and equipment, the influence of blasting vibration on the surrounding rock, etc. The five main factors are integrated: irregular construction, improper construction measures or poor quality, untimely support, insufficient support strength, and excessive construction disturbance.

Organizational Management Aspects. A total of 59 cases involved the administrative management aspects, accounting for $7.70 \%$. They are manifested in inadequate construction management, nonstandard construction, quality awareness, weak safety awareness, insufficient knowledge of dangers, insufficient knowledge of the changes and complexity of surrounding rock geological conditions, distortion of monitoring data, untimely feedback of monitoring information, and advanced geological forecasts. Three factors are integrated: low level of management awareness, failure of monitoring 
and measurement standards, and inadequate advance geological forecast.

Natural Aspects. Precipitation directly increases the surface water. If it encounters bad geological conditions, such as rock formations broken and cracks developed, it will cause surface water seepage. Seepage water causes the rock to soften and water gushing. It results in the stability of the surrounding rock deteriorating and the tunnel collapsing. Therefore, it is concluded that atmospheric rainfall is the leading natural factor that affects the collapse.

Step 7. Establishment of factor intrarelationships and relation matrix.

The relationship among system factors is determined by consulting experts to establish the relation matrix $\mathbf{M}_{0}$. The relation matrix $\mathbf{M}_{0}$ represents the relationship among system elements. It is an $n \times n$ order matrix, where $n$ represents the number of system elements, $M i$ means the rows of the matrix, and $M j$ represents the columns. If the element of row $M i$ affects the element of column $M j, M i j$ at the two nodes is represented by 1 ; in contrast, if the two are irrelevant, it is characterized by 0 :

$$
M_{i j}=\left\{\begin{array}{l}
1 \text { when } M_{i} \text { affects } M_{j}, \\
0 \text { when } M_{i} \text { does not affect } M_{j} .
\end{array}\right.
$$

Step 8. Calculation of reachability matrix.

The reachability matrix $\mathbf{M}_{1}=\left(\mathbf{M}_{0}+E\right)^{K+1}$ is calculated using Boolean algebra operations, in which the specific operation rules are shown in equations (5) and (6), where $E$ is the unit matrix.

$$
\begin{array}{rl}
0 & +0=0, \\
0 & +1=1, \\
1+1 & =1, \\
0 * 0 & =0, \\
0 * 10 & =0, \\
1 & * 1=1, \\
\left(M_{0}+E\right)^{1} \neq\left(M_{0}+E\right)^{2} \neq\left(M_{0}+E\right)^{3} \cdots \neq\left(M_{0}+E\right)^{K-1} & \\
\neq\left(M_{0}+E\right)^{K}=\left(M_{0}+E\right)^{K+1} \\
=M_{1}, \quad K>1 .
\end{array}
$$

Step 9. Hierarchical division of reachability matrix and determination of the factor level.

First, the reachability set $R(M i)$ and the antecedent set $Q(M j)$ are determined. The reachability set $R(M i)$ represents the set of factors that affect the column elements by the element $M i$ in each row. The antecedent set $Q(M j)$ represents the factors that each column element $M j$ has on the impact of the row elements. The reachability set $R(M i)$ in the factor set is the intersection of the reachability set and antecedent set $Q(M j)(R(M i)=R(M i) \cap Q(M j))$. Finally, the factors taken out for the first time are considered first-level indicators and then deleted from the statistical collection. This process is repeated until all factors are stratified.

Step 10. Drawing the directed graph.

Combined with the relation matrix $\mathbf{M}_{0}$, the directed graph is drawn by connecting the factors with directed arcs to express the relationship between two index factors.

3.2. Obtaining BN Probability. It is divided into five parts for using the fuzzy set theory to obtain the probability of $\mathrm{BN}$ nodes.

Step 11. BN structure diagram.

According to the first step, the ISM-directed graph of the tunnel collapse factors can be obtained. The circular relationship arcs are removed to meet the $\mathrm{BN}$ structural requirements using the directed graph correction method [42]. Then, the redundant arcs are deleted to reduce the complexity of the network structure and obtain the final $\mathrm{BN}$ structure diagram.

\section{Step 12. Expert natural language.}

The natural language expression is defined to construct the relationship among expert language variables and fuzzy numbers. A total of seven natural language variables are introduced: very low (VL), low (L), mildly low (ML), medium $(\mathrm{M})$, mildly high $(\mathrm{MH})$, high $(\mathrm{H})$, and very high $(\mathrm{VH})$ [30]. The membership functions corresponding to the seven linguistic variables are shown in Figure 4, and the corresponding triangular fuzzy numbers are listed in Table 2. The natural language variables of the factor nodes are obtained by consulting experts.

\section{Step 13. Aggregation of expert opinion.}

Personal experience and knowledge make experts hold different views on the same essential event. It is necessary to unify their opinions and reduce subjectivity. This paper uses the similarity aggregation method (SAM) to aggregate the experts' vague opinions. The details of SAM are discussed below [43].

First, the similarity between any two experts is calculated. The experts' natural language variables are converted into corresponding triangular fuzzy numbers according to Figure 4 and Table 2 . If the opinions of experts $E_{p}(p=1,2$, $\ldots, \mathrm{n})$ and experts $E_{q}(q=1,2, \ldots, n)$ are $E_{p}=\left(a_{1}, a_{2}, a_{3}\right)$ and $E_{q}=\left(b_{1}, b_{2}, b_{3}\right)$, respectively, the similarity function of the expert $E_{p}$ to the expert $E_{q}$ is

$$
S_{p q}=1-\frac{1}{3} \sum_{i=1}^{3}\left|a_{i}-b_{i}\right| .
$$

Second, the experts' average agreement $(A A(E p))$ is calculated as 


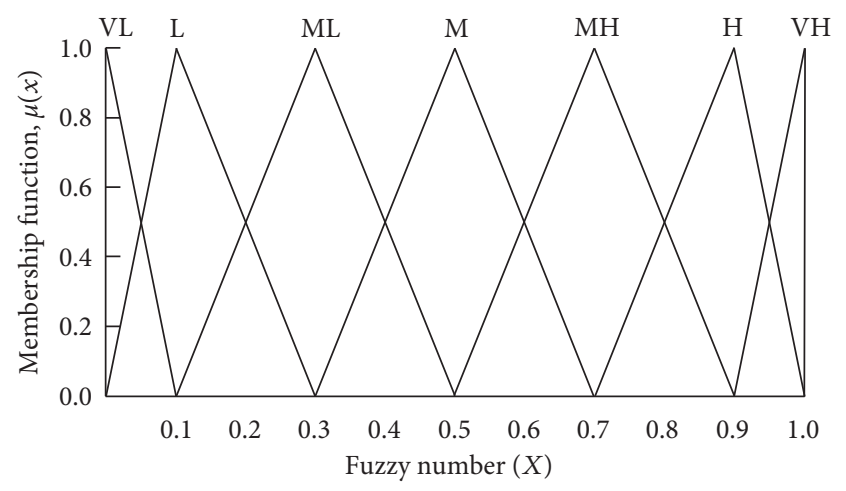

Figure 4: Membership function.

TABle 2: Triangular fuzzy numbers corresponding to language variables.

\begin{tabular}{lcc}
\hline Serial number & Language value & Fuzzy set \\
\hline 1 & $V L$ & $(0,0,0.1)$ \\
2 & $L$ & $(0,0.1,0.3)$ \\
3 & $M L$ & $(0.1,0.3,0.5)$ \\
4 & $M$ & $(0.3,0.5,0.7)$ \\
5 & $M H$ & $(0.5,0.7,0.9)$ \\
6 & $H$ & $(0.7,0.9,1.0)$ \\
7 & $V H$ & $(0.9,1.0,1.0)$ \\
\hline
\end{tabular}

$$
\operatorname{AAE}_{p}=\frac{1}{n-1} \sum_{\substack{q=1 \\ p \neq q}}^{n} S_{p q},
$$

where " $n$ " represents the total number of experts.

Third, the relative level of agreement $\left(R A\left(E_{p}\right)\right)$ is evaluated as

$$
\operatorname{RAE}_{p}=\frac{\operatorname{AA}\left(E_{p}\right)}{\sum_{p=1}^{n} \operatorname{AA}\left(E_{p}\right)}
$$

Fourth, the consensus coefficient $\left(C C\left(E_{p}\right)\right)$ is calculated as

$$
\begin{aligned}
g_{l} & =\sum_{i=1}^{3} A_{i}^{p}, \\
w\left(E_{p}\right) & =\frac{g_{l}}{\sum_{p=1}^{n} g_{l}}, \\
\mathrm{CC}\left(E_{p}\right) & =\beta \cdot w\left(E_{p}\right)+(1-\beta) \cdot \operatorname{RA}\left(E_{p}\right),
\end{aligned}
$$

where $A_{i}^{p}$ represents the score of the expert $p$ on the index $i$. Table 3 shows the specific quantitative scores; $w\left(E_{p}\right)$ and $\beta$ is a relaxation factor, which is 0.5 in this article.

Finally, the expert opinions are aggregated as

$$
E_{\mathrm{AG}}=\mathrm{CC}\left(E_{1}\right) \times E_{1}+\mathrm{CC}\left(E_{2}\right) \times E_{2}+\cdots+\mathrm{CC}\left(E_{n}\right) \times E_{n} .
$$

Step 14. Defuzzification.
Although expert opinions are aggregated, the results of $E A G$ are still a fuzzy number. The EAG's results require defuzzification processing to confirm the probability of factor nodes. The mean area method [44] is used to obtain the fuzzy possibility scores (FPSs):

$$
\begin{aligned}
\mathrm{FPS} & =P^{\prime} \\
& =\frac{s_{1}+2 s_{2}+s_{3}}{4} .
\end{aligned}
$$

Step 15. Determination of node probability.

The nodes' probability in different states are normalized to get the prior probability and conditional probability:

$$
P_{i}=\frac{P^{\prime}}{\sum_{i=1}^{2} P^{\prime}} .
$$

\subsection{Risk Analysis}

3.3.1. Risk Diagnosis and Reasoning. The tunnel collapse risk is diagnosed and analyzed in the GeNle software based on the BN structure diagram and the nodes' prior probability and conditional probability.

3.3.2. Sensitivity Analysis. Sensitivity analysis can determine the contribution of different factors, which is crucial to identify the key factors. The target node sensitivity analysis method is used to determine each factor's sensitivity to the target nodes. Its basic idea is as follows:

(1) The occurrence probability of each factor and the corresponding occurrence probability of the top event are determined.

(2) The latest occurrence probability of the top event is calculated under the occurrence of each factor node (the likelihood of node occurrence is one), respectively.

(3) Each factor node's influence on the top event is determined by comparing the latest occurrence probability of the top event with the increment of the original top event occurrence probability.

\section{Case Study}

4.1. Background. The model was used to predict the collapse possibility of the Canglongxia Tunnel in Ningshan, China, with a total length of $7,365.75 \mathrm{~m}$. This area belongs to the humid monsoon area on the fringe of the northern subtropical zone. The average precipitation is $877.1 \mathrm{~mm}$, and the rainfall is concentrated in July, August, and September. According to the geological survey report, the surrounding rocks of the Canglongxia Tunnel are relatively poor; the tunnel area passes through several faults and tectonic schistositized zones. The water inflow rate of the tunnel is predicted to be pretty significant by the water inflow estimation method. The maximum water inflow on the left line is $25,513 \mathrm{~m}^{3} / \mathrm{d}$, and the maximum water inflow on the right 
TABLE 3: Corresponding weights of indicators.

\begin{tabular}{lcc}
\hline Project & Grade & Weight points \\
\hline \multirow{3}{*}{ Job title } & Senior engineer & 5 \\
& Engineer & 4 \\
& Assistant engineer & 3 \\
& Technician & 2 \\
& Worker & 1 \\
\hline \multirow{3}{*}{ Length of service } & More than 20 years & 4 \\
& 10 20 years & 3 \\
& 5 10 years & 2 \\
Education & Less than 5 years & 1 \\
& Ph.D. student & 5 \\
& Postgraduate & 4 \\
& Undergraduate & 3 \\
& Specialist & 2 \\
& Other & 1 \\
\hline
\end{tabular}

line is $25,445 \mathrm{~m}^{3} / \mathrm{d}$, which brings great difficulties and challenges to the tunnel construction.

\subsection{Calculation Results}

4.2.1. Determination of FBN Structure Diagram by ISM. Table 4 lists the relation matrix $\mathbf{M}_{0}$ among the collapse factors determined according to the tunnel collapse factors (Table 1) and experts. Table 5 presents the calculation results of the reachability matrix $\mathbf{M}_{1}$. Table 6 shows the level partition summary. The directed graph based on ISM is demonstrated in Figure 5. Figure 6 shows the BN structure diagram.

The hierarchical relationship of tunnel collapse factors classified by ISM is shown in Table 6 . The hierarchical structure is divided into seven levels. The first level is target layer T0. The second level includes insufficient support strength Y12 and excessive construction disturbance Y13. The third level contains poor stability of surrounding rock $\mathrm{Y} 1$, irregular construction $\mathrm{Y} 9$, and untimely support Y11. The fourth level includes severe bias Y3, shallow buried Y4, improper construction measures or poor quality Y10, and failure of monitoring and measurement standards Y15; the fifth level contains two factors, namely, unreasonable design Y8 and low level of management awareness Y14; the sixth level includes only groundwater seepage Y6; the seventh level includes five elements, which are special poor geology conditions Y2, mutation of geological conditions Y5, inaccurate geological survey $\mathrm{Y} 7$, inadequate advance geological forecast Y16, and atmospheric rainfall Y17.

Based on the factor stratification results in Table 6 and the relation matrix $\mathbf{M}_{0}$ (Table 4), the directed graph based on the collapse factor of the ISM tunnel is obtained by using the directed arc to represent the relationship between the elements (Figure 5). Redundant arc connections and closed arcs are removed combined with expert opinions to meet the BN structure's requirements. Finally, a structural diagram conforming to the BN is obtained, as shown in Figure 6.
4.2.2. Probability of BN Nodes Obtained by Fuzzy Set Theory. We investigated five experts to obtain the probability of $\mathrm{BN}$ nodes. The specific steps are as follows: (1) obtaining the natural language value of the root nodes through experts; (2) converting natural language values into fuzzy sets; (3) aggregating expert opinions by SAM (the weights of five experts are shown in Table 7); (4) obtaining the node probability value using equations (14) and (15); and (5) obtaining the conditional probability of other nodes following the aforementioned steps.

Taking the root node low level of management awareness Y14 as an example, follow the above steps to obtain the node probability, and the specific results are shown in Table 8. The natural language values and the prior probability of all root nodes are shown in Table 9. Because of space limitations, only the conditional likelihood of groundwater seepage Y6 is selected, as shown in Table 10.

4.2.3. Risk Assessment Based on FBN Reasoning and Diagnosis. Figure 7 shows the calculation results. The probability of tunnel collapse is 0.177 . Table 11 counts each factor's occurrence probability, posterior probability, and ranking situation. The poor surrounding rock stability and inadequate advance geological forecast take the most extensive and lowest chance of 0.651 and 0.044 , respectively. Among the factors of geological aspects, the most considerable probability is the poor surrounding rock stability of 0.651 , and the lowest one is the mutation of geological conditions of 0.071 . Among the factors of survey and design aspects, the maximum probability of inaccurate geological survey is 0.157 , and the minimum possibility of unreasonable design is 0.077 ; among the factors of construction aspects, the maximum and minimum likelihood is irregular construction of 0.234 and improper construction measures or poor quality of 0.140 , respectively. Among the factors in organizational management aspects, the highest probability of 0.160 belongs to the low level of management awareness, and the lowest likelihood of 0.044 belongs to inadequate advance geological forecast. From Table 11, more changes can be found in the posterior probability, in which the factors with the highest occurrence probability are the poor stability of surrounding rock (0.662), excessive construction disturbance $(0.374)$, groundwater seepage $(0.325)$, atmospheric rainfall (0.273), special poor geological conditions (0.269), insufficient support strength (0.263), and irregular construction $(0.244)$. The ranking also indicates that the factors of construction aspects change largest in general. The two factors with the maximum changes are excessive construction disturbance of 0.162 and insufficient support strength of 0.109 . In contrast, the other factors share more minor changes.

4.2.4. Sensitivity Analysis. It can be determined which variable in the network is sensitive to the change of any other variable by sensitivity analysis. We can identify the child nodes that have the most significant impact on the tunnel 
Table 4: Relation matrix $\mathrm{M}_{0}$.

\begin{tabular}{lccccccccccccccccccc}
\hline Factor & $T 0$ & $Y 1$ & $Y 2$ & $Y 3$ & $Y 4$ & $Y 5$ & $Y 6$ & $Y 7$ & $Y 8$ & $Y 9$ & $Y 10$ & $Y 11$ & $Y 12$ & $Y 13$ & $Y 14$ & $Y 15$ & $Y 16$ & $Y 17$ \\
\hline T0 & 0 & 0 & 0 & 0 & 0 & 0 & 0 & 0 & 0 & 0 & 0 & 0 & 0 & 0 & 0 & 0 & 0 & 0 \\
$Y 1$ & 1 & 0 & 0 & 0 & 0 & 0 & 0 & 0 & 0 & 0 & 0 & 0 & 1 & 0 & 0 & 0 & 0 & 0 \\
$Y 2$ & 1 & 1 & 0 & 0 & 0 & 0 & 0 & 1 & 1 & 0 & 0 & 1 & 1 & 0 & 0 & 0 & 0 & 0 \\
$Y 3$ & 1 & 1 & 0 & 0 & 0 & 0 & 0 & 0 & 0 & 0 & 0 & 0 & 1 & 1 & 0 & 0 & 0 & 0 \\
$Y 4$ & 1 & 1 & 0 & 0 & 0 & 0 & 0 & 0 & 0 & 0 & 0 & 0 & 1 & 0 & 0 & 0 & 0 & 0 \\
$Y 5$ & 1 & 1 & 0 & 0 & 0 & 0 & 0 & 0 & 1 & 0 & 1 & 1 & 1 & 0 & 0 & 0 & 1 \\
$Y 6$ & 1 & 1 & 0 & 0 & 0 & 0 & 0 & 0 & 1 & 0 & 0 & 0 & 1 & 0 & 0 & 0 & 0 & 0 \\
$Y 7$ & 1 & 0 & 0 & 0 & 0 & 1 & 1 & 0 & 1 & 0 & 0 & 0 & 1 & 0 & 0 & 1 & 1 & 0 \\
$Y 8$ & 1 & 0 & 0 & 0 & 0 & 0 & 0 & 0 & 0 & 0 & 1 & 0 & 1 & 0 & 0 & 0 & 0 & 0 \\
$Y 9$ & 1 & 0 & 0 & 0 & 0 & 0 & 0 & 0 & 0 & 0 & 0 & 1 & 1 & 0 & 0 & 0 & 0 & 0 \\
$Y 10$ & 1 & 0 & 0 & 0 & 0 & 0 & 0 & 0 & 0 & 1 & 0 & 1 & 1 & 1 & 0 & 0 & 0 \\
$Y 11$ & 1 & 0 & 0 & 0 & 0 & 0 & 0 & 0 & 0 & 1 & 0 & 0 & 1 & 0 & 0 & 0 & 0 & 0 \\
$Y 12$ & 1 & 0 & 0 & 0 & 0 & 0 & 0 & 0 & 0 & 0 & 0 & 0 & 0 & 0 & 0 & 0 & 0 \\
$Y 13$ & 1 & 0 & 0 & 0 & 0 & 0 & 0 & 0 & 0 & 0 & 0 & 0 & 0 & 0 & 0 & 0 & 0 \\
$Y 14$ & 1 & 0 & 0 & 0 & 0 & 0 & 0 & 0 & 0 & 0 & 0 & 1 & 1 & 1 & 0 & 1 & 0 \\
$Y 15$ & 1 & 0 & 0 & 0 & 0 & 0 & 0 & 0 & 0 & 1 & 0 & 0 & 0 & 0 & 0 & 0 & 0 \\
$Y 16$ & 1 & 0 & 1 & 0 & 0 & 0 & 1 & 0 & 0 & 1 & 0 & 0 & 1 & 0 & 0 & 0 & 0 \\
$Y 17$ & 1 & 0 & 0 & 0 & 0 & 0 & 1 & 0 & 0 & 0 & 1 & 0 & 1 & 0 & 0 & 0 & 0 \\
\hline
\end{tabular}

TABle 5: Reachability matrix $\mathrm{M}_{1}$.

\begin{tabular}{|c|c|c|c|c|c|c|c|c|c|c|c|c|c|c|c|c|c|c|}
\hline Factor & T0 & $Y 1$ & $Y 2$ & $Y 3$ & $Y 4$ & $Y 5$ & $Y 6$ & $Y 7$ & $Y 8$ & $Y 9$ & $Y 10$ & $Y 11$ & $Y 12$ & $Y 13$ & $Y 14$ & $Y 15$ & $Y 16$ & $Y 17$ \\
\hline T0 & 1 & 0 & 0 & 0 & 0 & 0 & 0 & 0 & 0 & 0 & 0 & 0 & 0 & 0 & 0 & 0 & 0 & 0 \\
\hline$Y 1$ & 1 & 1 & 0 & 0 & 0 & 0 & 0 & 0 & 0 & 0 & 0 & 0 & 1 & 0 & 0 & 0 & 0 & 0 \\
\hline$Y 2$ & 1 & 1 & 1 & 0 & 0 & 1 & 1 & 1 & 1 & 1 & 1 & 1 & 1 & 1 & 0 & 1 & 1 & 0 \\
\hline$Y 3$ & 1 & 1 & 0 & 1 & 0 & 0 & 0 & 0 & 0 & 0 & 0 & 0 & 1 & 1 & 0 & 0 & 0 & 0 \\
\hline$Y 4$ & 1 & 1 & 0 & 0 & 1 & 0 & 0 & 0 & 0 & 0 & 0 & 0 & 1 & 0 & 0 & 0 & 0 & 0 \\
\hline$Y 5$ & 1 & 1 & 1 & 0 & 0 & 1 & 1 & 1 & 1 & 1 & 1 & 1 & 1 & 1 & 0 & 1 & 1 & 0 \\
\hline Y6 & 1 & 1 & 0 & 0 & 0 & 0 & 1 & 0 & 1 & 1 & 1 & 1 & 1 & 1 & 0 & 0 & 0 & 0 \\
\hline$Y 7$ & 1 & 1 & 1 & 0 & 0 & 1 & 1 & 1 & 1 & 1 & 1 & 1 & 1 & 1 & 0 & 1 & 1 & 0 \\
\hline$Y 8$ & 1 & 0 & 0 & 0 & 0 & 0 & 0 & 0 & 1 & 1 & 1 & 1 & 1 & 1 & 0 & 0 & 0 & 0 \\
\hline$Y 9$ & 1 & 0 & 0 & 0 & 0 & 0 & 0 & 0 & 0 & 1 & 0 & 1 & 1 & 0 & 0 & 0 & 0 & 0 \\
\hline$Y 10$ & 1 & 0 & 0 & 0 & 0 & 0 & 0 & 0 & 0 & 1 & 1 & 1 & 1 & 1 & 0 & 0 & 0 & 0 \\
\hline$Y 11$ & 1 & 0 & 0 & 0 & 0 & 0 & 0 & 0 & 0 & 1 & 0 & 1 & 1 & 0 & 0 & 0 & 0 & 0 \\
\hline$Y 12$ & 1 & 0 & 0 & 0 & 0 & 0 & 0 & 0 & 0 & 0 & 0 & 0 & 1 & 0 & 0 & 0 & 0 & 0 \\
\hline$Y 13$ & 1 & 0 & 0 & 0 & 0 & 0 & 0 & 0 & 0 & 0 & 0 & 0 & 0 & 1 & 0 & 0 & 0 & 0 \\
\hline$Y 14$ & 1 & 0 & 0 & 0 & 0 & 0 & 0 & 0 & 0 & 1 & 0 & 1 & 1 & 1 & 1 & 1 & 0 & 0 \\
\hline$Y 15$ & 1 & 0 & 0 & 0 & 0 & 0 & 0 & 0 & 0 & 1 & 0 & 1 & 1 & 0 & 0 & 1 & 0 & 0 \\
\hline$Y 16$ & 1 & 1 & 1 & 0 & 0 & 1 & 1 & 1 & 1 & 1 & 1 & 1 & 1 & 1 & 0 & 1 & 1 & 0 \\
\hline$Y 17$ & 1 & 1 & 0 & 0 & 0 & 0 & 1 & 0 & 1 & 1 & 1 & 1 & 1 & 1 & 0 & 0 & 0 & 1 \\
\hline
\end{tabular}

TABLE 6: Level partition summary.

\begin{tabular}{|c|c|c|c|c|}
\hline Factor & Reachability set $R\left(M_{i}\right)$ & Antecedent set $Q\left(M_{j}\right)$ & $R\left(M_{i}\right) \cap Q\left(M_{j}\right)$ & Level \\
\hline T0 & 0 & $0,1,2,3,4,5,6,7,8,9,10,11,12,14,15,16,17$ & 0 & I \\
\hline$Y 1$ & $0,1,12$ & $1,2,3,4,5,6,7,16,17$ & 1 & III \\
\hline$Y 2$ & $0,1,2,5,6,7,8,9,10,11,12,13,15,16$ & $2,5,7,16$ & $2,5,7,16$ & VII \\
\hline$Y 3$ & $0,1,3,12,13$ & 3 & 3 & IV \\
\hline Y4 & $0,1,4,12$ & 4 & 4 & IV \\
\hline$Y 5$ & $0,1,2,5,6,7,8,9,10,11,12,13,15,16$ & $2,5,7,16$ & $2,5,7,16$ & VII \\
\hline Y6 & $0,1,6,8,9,10,11,12,13$ & $2,5,6,7,16,17$ & 6 & VI \\
\hline$Y 7$ & $0,1,2,5,6,7,8,9,10,11,12,13,15,16$ & $2,5,7,16$ & $2,5,7,16$ & VII \\
\hline Y8 & $0,8,9,10,11,12,13$ & $2,5,6,7,8,16,17$ & 8 & $\mathrm{~V}$ \\
\hline$Y 9$ & $0,9,11,12$ & $2,5,6,7,8,9,10,11,14,15,16,17$ & 9,11 & III \\
\hline$Y 10$ & $0,9,10,11,12,13$ & $2,5,6,7,8,10,16,17$ & 10 & IV \\
\hline$Y 11$ & $0,9,11,12$ & $2,5,6,7,8,9,10,11,14,15,16,17$ & 9,11 & III \\
\hline$Y 12$ & 0,12 & $1,2,3,4,5,6,7,8,9,10,11,12,14,15,16,17$ & 12 & II \\
\hline$Y 13$ & 0,13 & $2,3,5,6,7,8,10,13,14,16,17$ & 13 & II \\
\hline$Y 14$ & $0,9,11,12,13,14,15$ & 14 & 14 & $\mathrm{~V}$ \\
\hline$Y 15$ & $0,9,11,12,15$ & $2,5,7,14,15,16$ & 15 & IV \\
\hline$Y 16$ & $0,1,2,5,6,7,8,9,10,11,12,13,15,16$ & $2,5,7,16$ & $2,5,7,16$ & VII \\
\hline Y17 & $0,1,6,8,9,10,11,12,13,17$ & 17 & 17 & VII \\
\hline
\end{tabular}




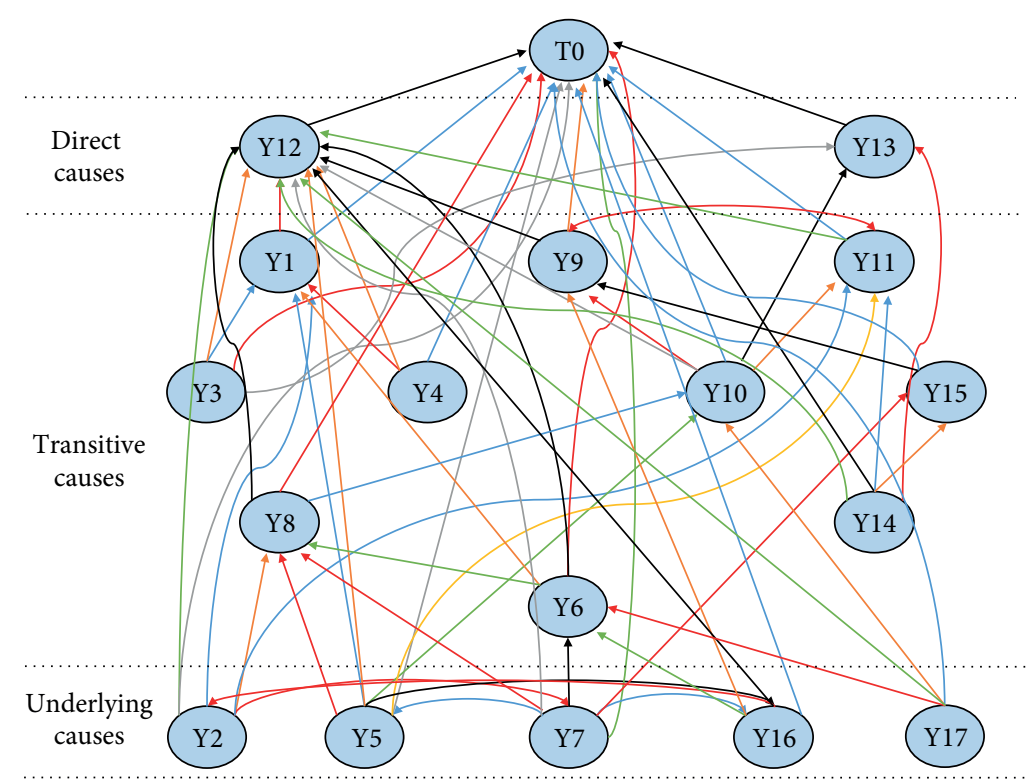

FIgURE 5: The directed graph of ISM.

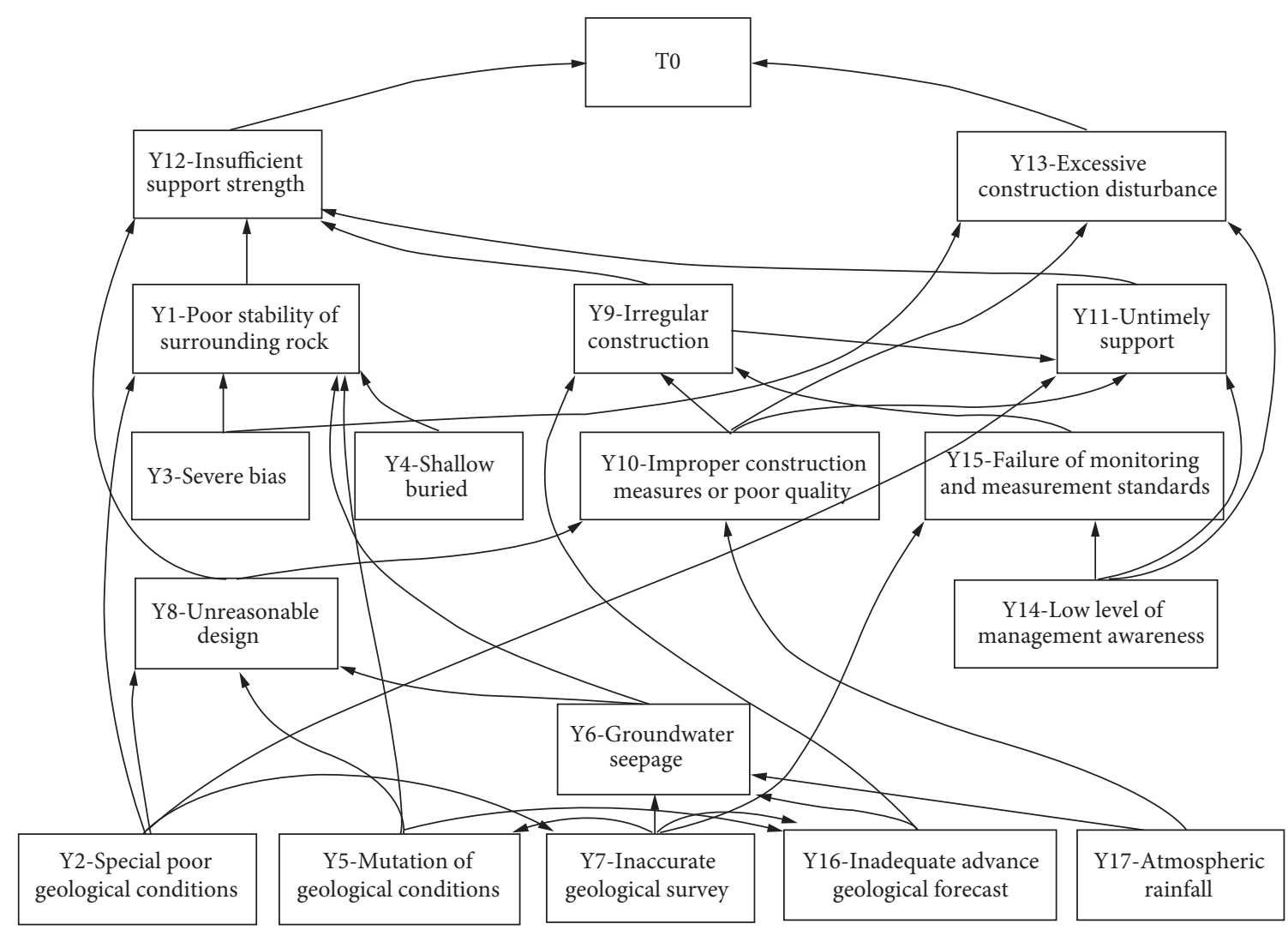

FIgURE 6: The structure diagram of BN.

collapse node. Table 12 lists the sensitivity analysis results. Excessive construction disturbance and insufficient support strength are the two factors that significantly impact tunnel collapse.

Analyzing the impacts of related factors on the two key elements is crucial to reducing the risk of tunnel collapse.
When irregular construction occurs, the probability of excessive construction disturbance increases to $23.4 \%$, and the likelihood of insufficient support strength rises to $17.8 \%$. Figure 8 shows the probability change of insufficient support strength and excessive construction disturbance under the occurrence of each factor node. 
TABLE 7: Weights of five experts.

\begin{tabular}{|c|c|c|c|c|}
\hline Expert & Job title/weight points & Length of service (years)/weight points & Education/weight points & Weights \\
\hline$E_{1}$ & Senior engineer $/ 5$ & $18 / 3$ & Ph.D. student $/ 5$ & $13 / 51=0.255$ \\
\hline$E_{2}$ & Engineer/4 & $21 / 4$ & Undergraduate/3 & $11 / 51=0.216$ \\
\hline$E_{3}$ & Assistant engineer/3 & $3 / 1$ & Postgraduate/4 & $8 / 51=0.157$ \\
\hline$E_{4}$ & Engineer/4 & $13 / 3$ & Undergraduate/3 & $10 / 51=0.196$ \\
\hline$E_{5}$ & Engineer/4 & $17 / 3$ & Specialist/2 & $9 / 51=0.176$ \\
\hline
\end{tabular}

TABLE 8: A priori probability calculation result of root node $Y 14$.

\begin{tabular}{|c|c|c|c|c|c|}
\hline Parameter symbol & Numerical value & Parameter symbol & Numerical value & Parameter symbol & Numerical value \\
\hline$\overline{E_{1}}$ & $L(0,0.1,0.3)$ & $S_{12}$ & 0.83333 & $S_{24}$ & 0.83333 \\
\hline$E_{2}$ & $\operatorname{ML}(0.1,0.3,0.5)$ & $S_{13}$ & 1.00000 & $S_{25}$ & 0.83333 \\
\hline$E_{3}$ & $L(0,0.1,0.3)$ & $S_{14}$ & 1.00000 & $S_{34}$ & 1.00000 \\
\hline$E_{4}$ & $L(0,0.1,0.3)$ & $S_{15}$ & 1.00000 & $S_{35}$ & 1.00000 \\
\hline$E_{5}$ & $L(0,0.1,0.3)$ & $S_{23}$ & 0.83333 & $S_{45}$ & 1.00000 \\
\hline$A A\left(E_{1}\right)$ & 0.95833 & $R A\left(E_{1}\right)$ & 0.20536 & $w\left(E_{1}\right)$ & 0.25500 \\
\hline$A A\left(E_{2}\right)$ & 0.83333 & $R A\left(E_{2}\right)$ & 0.17856 & $w\left(E_{2}\right)$ & 0.21600 \\
\hline$A A\left(E_{3}\right)$ & 0.95833 & $R A\left(E_{3}\right)$ & 0.20536 & $w\left(E_{3}\right)$ & 0.15700 \\
\hline$A A\left(E_{4}\right)$ & 0.95833 & $R A\left(E_{4}\right)$ & 0.20536 & $w\left(E_{4}\right)$ & 0.19600 \\
\hline$A A\left(E_{5}\right)$ & 0.95833 & $R A\left(E_{5}\right)$ & 0.20536 & $w\left(E_{5}\right)$ & 0.17600 \\
\hline$C C\left(E_{1}\right)$ & 0.23018 & & & & \\
\hline$C C\left(E_{2}\right)$ & 0.19728 & & & & \\
\hline$C C\left(E_{3}\right)$ & 0.18118 & $E_{A G}$ & $(0.019728,0.139456,0.339456)$ & $P$ & 0.160 \\
\hline$C C\left(E_{4}\right)$ & 0.20068 & & & & \\
\hline $\operatorname{CC}\left(E_{5}\right)$ & 0.19068 & & & & \\
\hline
\end{tabular}

TABLE 9: Natural language value, aggregation result, and the prior probability of root node experts.

\begin{tabular}{lccccccc}
\hline Root node & $E_{1}$ & $E_{2}$ & $E_{3}$ & $E_{4}$ & $E_{5}$ & $E_{A G}$ \\
\hline$Y 2$ & $M L$ & $L$ & $M L$ & $M L$ & $M L$ & $(0.080272,0.260544,0.460544)$ & 0.265 \\
$Y 3$ & $L$ & $L$ & $V L$ & $L$ & $L$ & $(0,0.082771,0.265550)$ & 0.108 \\
$Y 4$ & $L$ & $L$ & $M L$ & $L$ & $L$ & $(0.016779,0.133557,0.333557)$ & 0.154 \\
$Y 14$ & $L$ & $M L$ & $L$ & $L$ & $L$ & $(0.019728,0.139456,0.339456)$ & 0.160 \\
$Y 17$ & $M L$ & $M L$ & $L$ & $M L$ & $M$ & $(0.083222,0.266444,0.466444)$ \\
\hline
\end{tabular}

TABLE 10: The conditional probability of node $Y 6$ with respect to $Y 7, Y 16$, and $Y 17$.

\begin{tabular}{ccccccccccc}
\hline Root node & $Y 7$ & $Y 16$ & Y17 & $E_{1}$ & $E_{2}$ & $E_{3}$ & $E_{4}$ & $E_{5}$ & Yes & No \\
\hline \multirow{6}{*}{$Y$} & $Y$ & $Y$ & $Y$ & $M$ & $M H$ & $M$ & $M H$ & $M H$ & 0.620 & 0.380 \\
& $Y$ & $Y$ & $N$ & $M L$ & $M L$ & $M$ & $M$ & $M$ & 0.414 & 0.586 \\
& $Y$ & $N$ & $Y$ & $M L$ & $M L$ & $L$ & $L$ & $L$ & 0.200 \\
& $Y$ & $N$ & $N$ & $M$ & $M$ & $M$ & $M$ & $M$ & 0.800 \\
& $N$ & $Y$ & $Y$ & $M H$ & $M H$ & $M H$ & $M H$ & $H$ & 0.731 & 0.500 \\
& $N$ & $Y$ & $N$ & $M L$ & $M L$ & $M$ & $M$ & $M$ & 0.414 & 0.586 \\
& $N$ & $N$ & $Y$ & $M L$ & $M L$ & $L$ & $L$ & $L$ & 0.200 & 0.800 \\
& $N$ & $N$ & $N$ & $M L$ & $M L$ & $M$ & $M L$ & $M L$ & 0.333 & 0.667 \\
\hline
\end{tabular}

The figure shows that unreasonable design (13.2\%) is the main factor affecting insufficient support strength, and improper construction measures or poor quality $(12.8 \%)$ has the highest impact on excessive construction disturbance. To sum up, the factors of construction aspects are still the main body to affect these two key factors. In other words, the human element is the basis of these errors. In brief, managers must strengthen the management and training of field personnel.

\section{Discussion}

Collapse, as one of the essential risks during tunnel construction, may cause economic loss and casualties. The risks associated with the tunnel collapse are quite complex since the relationships between the variables are not linear. This paper proposes an ISM-FBN method to solve the limitation in tunnel collapse risk assessment that the interactions among risk factors are not considered. Specifically, ISM is 


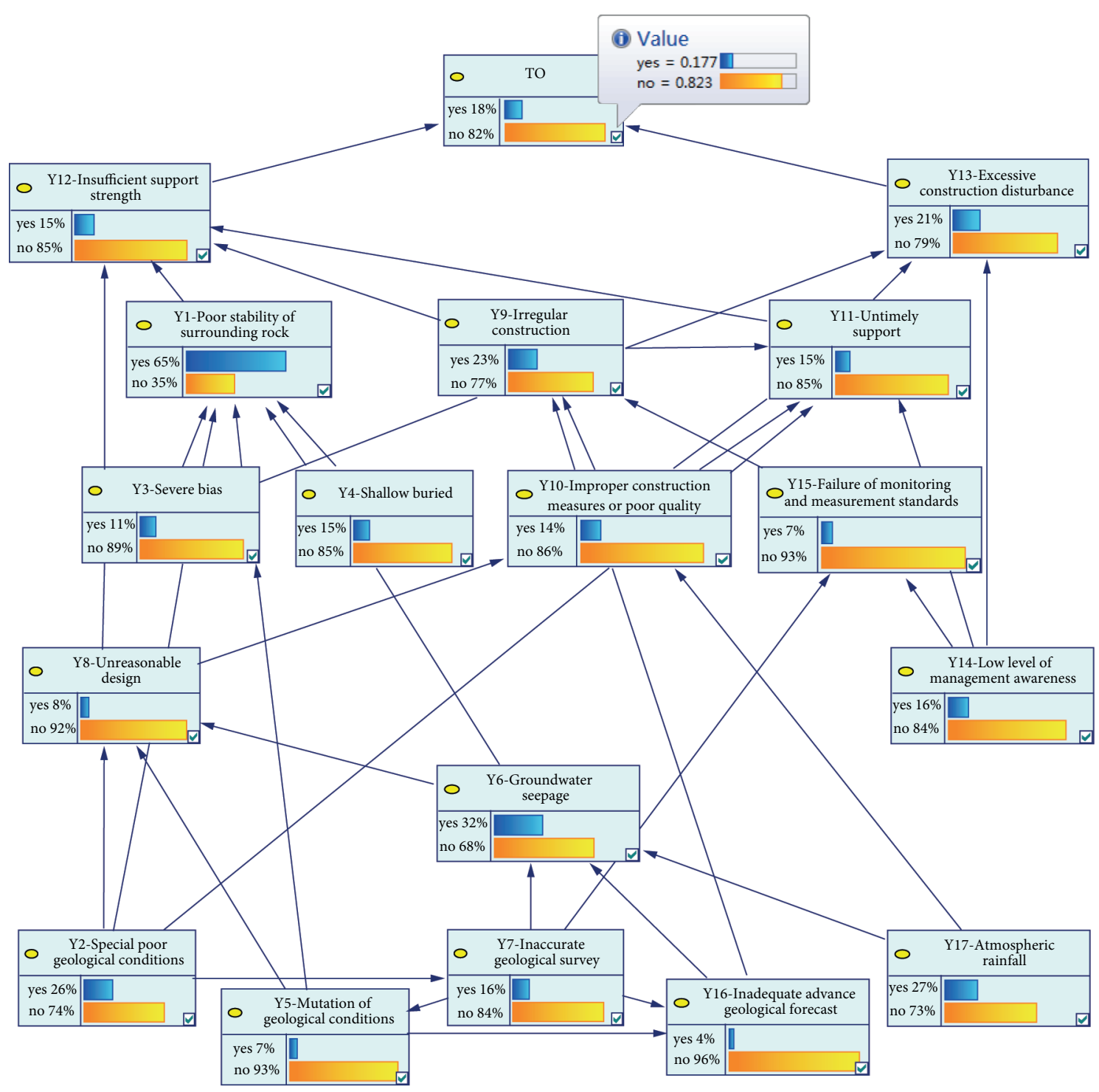

FIgURE 7: Bayesian network model.

used to determine the hierarchical relationship between risk factors. FBN quantifies the strength of the interaction among risk factors and conducts risk analysis. The proposed method is also used to assess the potential collapse risks in the Canglongxia Tunnel.

This study uses ISM to realize the layering of tunnel collapse factors. The factors can be divided into three levels, i.e., direct causes, transitive causes, and underlying causes. Qualitatively, the ISM identifies insufficient support strength and excessive construction disturbance as the immediate causes. The transitive causes include poor stability of surrounding rock, irregular construction, untimely support, severe bias, shallow buried, improper construction measures or poor quality, failure of monitoring and measurement standards, unreasonable design, low level of management awareness, and groundwater seepage. The underlying causes include special poor geology conditions, mutation of geological conditions, inaccurate geological survey, inadequate advance geological forecast, and atmospheric rainfall.
It was found that direct causes, including insufficient support strength and excessive construction disturbance, are the most critical risks affecting tunnel collapse. To minimize the risks, we should control its impact during the actual process. To begin with, the crew of the construction should be trained about the threat during tunnel construction. Then, construction workers should be forced to follow the design and building codes during tunnel construction strictly. Last but not least, do well in monitoring and surveying work of tunnel construction, dynamically monitor geological changes in the tunnel construction process, and strengthen safety management and safety inspection of the tunnel construction site.

Meanwhile, it should be noted that multiple factors affect the risk of tunnel collapse. We need to pay attention to the transitive causes and underlying causes that affect direct causes, especially the underlying causes, which are considered the root cause of the tunnel collapse. These factors should be prevented and handled during the construction, 
TABLE 11: Occurrence probability, posterior probability, and ranking of each factor.

\begin{tabular}{|c|c|c|c|c|c|c|}
\hline \multirow[t]{2}{*}{ Total index } & \multirow[t]{2}{*}{ Factor } & \multicolumn{2}{|c|}{$\begin{array}{c}\text { Probability of } \\
\text { occurrence }\end{array}$} & \multicolumn{3}{|c|}{ Posterior probability } \\
\hline & & Yes & Rank & Yes & Probability change & Rank \\
\hline \multirow{6}{*}{ Geological aspects } & $Y 1$ & 0.651 & 1 & 0.662 & 0.011 & 4 \\
\hline & $Y 2$ & 0.265 & 4 & 0.269 & 0.004 & 10 \\
\hline & $Y 3$ & 0.108 & 13 & 0.114 & 0.006 & 8 \\
\hline & $Y 4$ & 0.154 & 9 & 0.154 & 0.000 & 14 \\
\hline & $Y 5$ & 0.071 & 15 & 0.071 & 0.000 & 14 \\
\hline & Y6 & 0.324 & 2 & 0.325 & 0.001 & 12 \\
\hline \multirow{2}{*}{ Survey and design aspects } & $Y 7$ & 0.157 & 8 & 0.157 & 0.000 & 14 \\
\hline & Y8 & 0.077 & 14 & 0.087 & 0.010 & 5 \\
\hline \multirow{5}{*}{ Construction aspects } & $Y 9$ & 0.234 & 5 & 0.244 & 0.010 & 5 \\
\hline & $Y 10$ & 0.140 & 12 & 0.161 & 0.021 & 3 \\
\hline & $Y 11$ & 0.146 & 11 & 0.155 & 0.009 & 7 \\
\hline & $Y 12$ & 0.154 & 10 & 0.263 & 0.109 & 2 \\
\hline & $Y 13$ & 0.212 & 6 & 0.374 & 0.162 & 1 \\
\hline \multirow{3}{*}{ Organizational management aspects } & $Y 14$ & 0.160 & 7 & 0.166 & 0.006 & 8 \\
\hline & $Y 15$ & 0.068 & 16 & 0.069 & 0.001 & 12 \\
\hline & $Y 16$ & 0.044 & 17 & 0.044 & 0.000 & 14 \\
\hline Natural aspects & $Y 17$ & 0.271 & 3 & 0.273 & 0.002 & 11 \\
\hline
\end{tabular}

TABLE 12: Sensitivity analysis result.

\begin{tabular}{|c|c|c|c|c|}
\hline Risk factor & $\begin{array}{c}\text { Probability of } \\
\text { occurrence (\%) }\end{array}$ & $\begin{array}{l}\text { Original collapse } \\
\text { probability }(\%)\end{array}$ & $\begin{array}{c}\text { New collapse } \\
\text { probability (\%) }\end{array}$ & $\begin{array}{c}\text { Probability change } \\
(\%)\end{array}$ \\
\hline Excessive construction disturbance & 21.2 & 17.7 & 31.1 & 13.4 \\
\hline Insufficient support strength & 15.4 & 17.7 & 30.2 & 12.5 \\
\hline $\begin{array}{l}\text { Improper construction measures or } \\
\text { poor quality }\end{array}$ & 14.0 & 17.7 & 20.3 & 2.6 \\
\hline Unreasonable design & 7.7 & 17.7 & 19.9 & 2.2 \\
\hline Untimely support & 14.6 & 17.7 & 18.7 & 1.0 \\
\hline Severe bias & 10.8 & 17.7 & 18.6 & 0.9 \\
\hline Irregular construction & 23.4 & 17.7 & 18.5 & 0.8 \\
\hline Low level of management awareness & 16.0 & 17.7 & 18.3 & 0.6 \\
\hline Poor stability of surrounding rock & 65.1 & 17.7 & 18.0 & 0.3 \\
\hline Special poor geological conditions & 26.5 & 17.7 & 18.0 & 0.3 \\
\hline $\begin{array}{l}\text { Failure of monitoring and } \\
\text { measurement standards }\end{array}$ & 6.8 & 17.7 & 17.8 & 0.1 \\
\hline Atmospheric rainfall & 27.1 & 17.7 & 17.8 & 0.1 \\
\hline Shallow buried & 15.4 & 17.7 & 17.7 & 0.0 \\
\hline Mutation of geological conditions & 7.1 & 17.7 & 17.7 & 0.0 \\
\hline Groundwater seepage & 32.4 & 17.7 & 17.7 & 0.0 \\
\hline Inaccurate geological survey & 15.7 & 17.7 & 17.7 & 0.0 \\
\hline Inadequate advance geological forecast & 4.4 & 17.7 & 17.7 & 0.0 \\
\hline
\end{tabular}

rather than just focusing on the direct reasons causing the accidents.

This article summarizes 17 factors that affect tunnel collapse. There are still some factors needed to be considered. Meanwhile, the data in the $\mathrm{BN}$ model are driven by the experts' opinions. To reduce the subjectivity of experts' opinions as much as possible, SAM is introduced to aggregate experts' views. The results of the case study show that reasonable and objective sample data can improve the simulation results. 


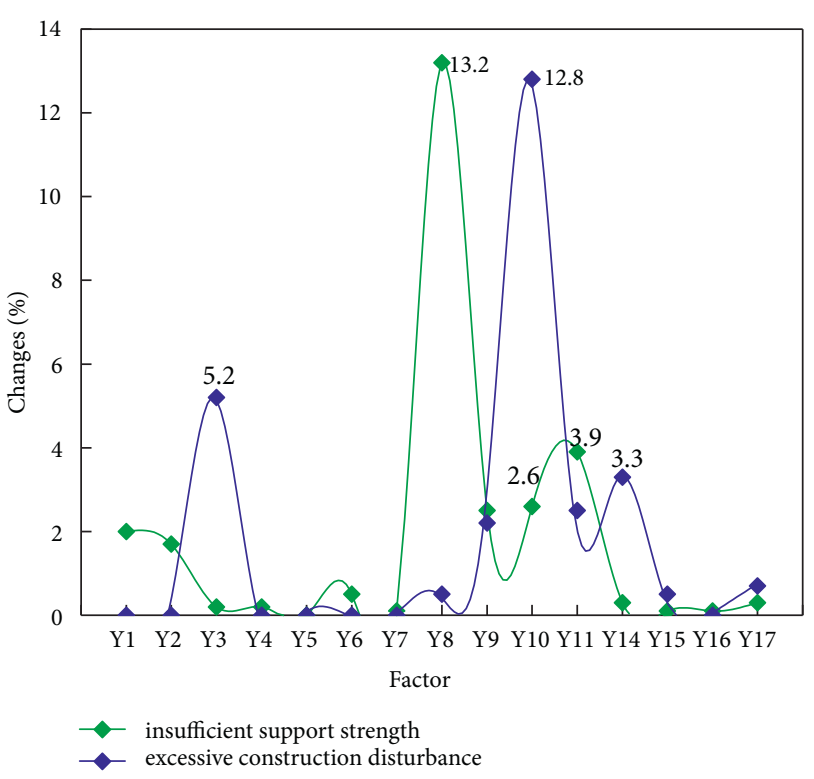

Figure 8: Probability change difference of the influence of various factors on insufficient support strength and excessive construction disturbance.

\section{Conclusions}

An ISM-FBN method is proposed to quantify the tunnel collapse risk to establish the interaction relationship among the factors affecting the tunnel collapse. First, ISM constructs a hierarchical relationship of factors to develop the preliminary BN structure diagram. Next, the nodes' prior probability and conditional probability are obtained by using SAM to aggregate expert opinions. Eventually, the GeNle software is used to realize $\mathrm{BN}$ reasoning and diagnosis.

The proposed ISM-FBN method can determine the interaction relationship among risk factors. It also can identify the critical elements based on sensitivity analysis, which provides a decision-making basis for preventing risk accidents and guides the risk control work. This method predicts the potential collapse risk in the Canglongxia Tunnel, which verifies the ISM-FBN method's feasibility.

\section{Data Availability}

The data underlying the results presented in the study are included within the article.

\section{Conflicts of Interest}

The authors declare that there are no conflicts of interest.

\section{Acknowledgments}

This study was funded by the National Natural Science Foundation of China (52178357 and 52078442) and Sichuan Science and Technology Program (2019JDJQ0037, 2020JDRC0091, and 2021YFSY0006). The authors also acknowledge 2nd Department of China Railway Tunnel Group Co., Ltd., for the financial support.

\section{References}

[1] J. L Sun, Study on Collapse Risk and Stability Evaluation in Mining Construction of Mountain Tunnel, Beijing Jiaotong University, Beijing China, (in Chinese), 2019.

[2] W. Chen, G. H. Zhang, H. Wang, G. Q Zhong, and C. T Wang, "Evaluation of possibility of tunnel collapse by drilling and blasting method based on T-S fuzzy fault tree," Rock and Soil Mechanics, vol. 40, pp. 319-328, 2019, (in Chinese).

[3] C. X Zhang, S. C. Wu, and J. Wu, "Study on risk assessment model of collapse during construction of mountain tunnel and its application," Journal of Safety Science and Technology, vol. 15, pp. 128-134, 2019, (in Chinese).

[4] G. H. Zhang, Y. Y. Jiao, L. B. Chen, H. Wang, and S. C. Li, "Analytical model for assessing collapse risk during mountain tunnel construction," Canadian Geotechnical Journal, vol. 53, no. 2, pp. 326-342, 2016.

[5] Y. Yuan, S. C. Li, L. Li, T. Lei, and B. Sun, "Risk evaluation theory and method of collapse in mountain tunnel and its engineering applications," Journal of Central South University, vol. 47, no. 7, pp. 2407-2414, 2016.

[6] S. Wang, L. P. Li, S. Cheng, H. Hu, H. Jin, and S. Gao, "Dynamic risk assessment method of tunnel collapse based on attribute interval assessment model and application," Polish Journal of Environmental Studies, vol. 29, no. 5, pp. 3853-3864, 2020.

[7] J. Sun, B. Liu, Z. Chu, L. Chen, and X. Li, "Tunnel collapse risk assessment based on multistate fuzzy Bayesian networks," Quality and Reliability Engineering International, vol. 34, no. 8, pp. 1646-1662, 2018.

[8] W. Chen, G. H. Zhang, H. Wang, and L. B Chen, "Risk assessment of mountain tunnel collapse based on rough set and conditional information entropy," Rock and Soil Mechanics, vol. 40, pp. 3549-3558, 2019, (in Chinese).

[9] Y. Xue, X. Li, G. Li, D. Qiu, and F. Kong, "An analytical model for assessing soft rock tunnel collapse risk and its engineering application," Geomechanics and Engineering, vol. 23, no. 5, pp. 441-454, 2020.

[10] E. Zio, "Challenges in the vulnerability and risk analysis of critical infrastructures," Reliability Engineering \& System Safety, vol. 152, pp. 137-150, 2016.

[11] C. K. Allison, K. M. Revell, R. Sears, and N. A. Stanton, "Systems Theoretic Accident Model and Process (STAMP) safety modelling applied to an aircraft rapid decompression event," Safety Science, vol. 98, pp. 159-166, 2017.

[12] I. Friedberg, K. Mclaughlin, P. Smith, D. Laverty, and S. Sezer, "STPA-SafeSec: safety and security analysis for cyber-physical systems," Journal of Information Security and Applications, vol. 34, pp. 183-196, 2016.

[13] J. Tian, J. Wu, Q. Yang, and T. Zhao, "FRAMA: a safety assessment approach based on Functional Resonance Analysis Method," Safety Science, vol. 85, pp. 41-52, 2016.

[14] G. Fu, J. Cao, and X. Wang, "Relationship analysis of causal factors in coal and gas outburst accidents based on the 24Model,” Energy Procedia, vol. 107, pp. 314-320, 2017.

[15] M. Manoj and A. Verma, "A structural equation model based analysis of non-workers' activity-travel behaviour from a city of a developing country," Transportation, vol. 44, no. 2, pp. 241-269, 2015.

[16] L. S. Rowles, T. Whittaker, P. M. Ward et al., "A structural equation model to decipher relationships among water, sanitation, and health in colonias-type unincorporated communities," Environmental Science \& Technology, vol. 54, no. 24, Article ID 16017, 2020. 
[17] F. Talib, Z. Rahman, and M. N. Qureshi, "Analysis of interaction among the barriers to total quality management implementation using interpretive structural modeling approach," Benchmarking: An International Journal, vol. 18, no. 4, pp. 563-587, 2011.

[18] K. Govindan, M. Palaniappan, Q. Zhu, and D. Kannan, "Analysis of third party reverse logistics provider using interpretive structural modeling," International Journal of Production Economics, vol. 140, no. 1, pp. 204-211, 2012.

[19] P. Franchin, A. Lupoi, F. Noto, and S. Tesfamariam, "Seismic fragility of reinforced concrete girder bridges using Bayesian belief network," Earthquake Engineering \& Structural Dynamics, vol. 45, no. 1, pp. 29-44, 2016.

[20] C. Chen, X. Liu, H. H. Chen, M. Li, and L. Zhao, "A rear-end collision risk evaluation and control scheme using a bayesian network model," IEEE Transactions on Intelligent Transportation Systems, vol. 20, no. 1, pp. 264-284, 2019.

[21] T. N. Zang, X. C. Yun, Y. Z. Zhang, and C. G. Men, “A botnet migration analyzer based on the C-F model," Geomatics and Information Science of Wuhan University, vol. 35, no. 5, pp. 622-625, 2010, (in Chinese).

[22] K. Yuan, F. Xiao, L. Fei, B. Kang, and Y. Deng, "Modeling sensor reliability in fault diagnosis based on evidence theory," Sensors, vol. 16, no. 1, 2016.

[23] J. H. Huang, S. Yang, and B. Wu, "Construction risk assessment of foundation pit engineering based on methods of Bayesian network," Engineering Journal of Wuhan University, vol. 49, no. 5, pp. 733-739, 2016, (in Chinese).

[24] X. Li, L. Zhang, and S. Zhang, "Efficient Bayesian networks for slope safety evaluation with large quantity monitoring information," Geoscience Frontiers, vol. 9, no. 6, pp. 1679-1687, 2017.

[25] D. Qiu, C. Qu, Y. Xue et al., “A comprehensive assessment method for safety risk of gas tunnel construction based on fuzzy bayesian network," Polish Journal of Environmental Studies, vol. 29, no. 6, pp. 4269-4289, 2020.

[26] E. Lee, Y. Park, and J. G. Shin, "Large engineering project risk management using a Bayesian belief network," Expert Systems with Applications, vol. 36, no. 3, pp. 5880-5887, 2009.

[27] B. Yet, A. Constantinou, N. Fenton, M. Neil, E. Luedeling, and K. Shepherd, "A Bayesian network framework for project cost, benefit and risk analysis with an agricultural development case study," Expert Systems with Applications, vol. 60, pp. 141-155, 2016.

[28] X. Wang, J. Zhu, F. B Ma, C. H. Li, Y. P. Cai, and Z. F. Yang, "Bayesian network-based risk assessment for hazmat transportation on the middle route of the south-to-north water transfer project in China," Stochastic Environmental Research and Risk Assessment, vol. 30, no. 2, pp. 841-857, 2016.

[29] A. Namazian, S. H. Yakhchali, V. Yousefi, and J. Tamošaitiene,, "Combining Monte Carlo simulation and bayesian networks methods for assessing completion time of projects under risk," International Journal of Environmental Research and Public Health, vol. 16, no. 24, p. 5024, 2019.

[30] C. T Wang, H. Wang, W. M. Qin, G. Q. Zhong, and W. Chen, "Evaluation of collapse possibility of deep foundation pits in metro stations based on multi-state fuzzy Bayesian networks," Rock and Soil Mechanics, vol. 41, no. 5, pp. 1670-1679+1689, 2020, (in Chinese).

[31] J. Ren, I. Jenkinson, J. Wang, D. L Xu, and J. B Yang, "An offshore risk analysis method using fuzzy bayesian network," Journal of Offshore Mechanics and Arctic Engineering, vol. 131, no. 4, Article ID 041101, 2009.
[32] W. Mechri, W. Snene, and K. B. Othman, "Uncertainties handling in safety system performance assessment by using fuzzy Bayesian networks," Journal of Intelligent and Fuzzy Systems, vol. 33, no. 2, pp. 995-1006, 2017.

[33] M. M. Aliabadi, A. Pourhasan, and I. Mohammadfam, "Risk modelling of a hydrogen gasholder using Fuzzy Bayesian Network (FBN)," International Journal of Hydrogen Energy, vol. 45, no. 1, pp. 1177-1186, 2019.

[34] B. B. Gardas, R. D. Raut, and B. Narkhede, "Identifying critical success factors to facilitate reusable plastic packaging towards sustainable supply chain management," Journal of Environmental Management, vol. 236, pp. 81-92, 2019.

[35] M. N. Faisal and F. Talib, "Implementing traceability in Indian food-supply chains: an interpretive structural modeling approach," Journal of Foodservice Business Research, vol. 19, no. 2, pp. 171-196, 2016.

[36] G. Li, D. Huang, C. Sun, and Y. Li, "Developing interpretive structural modeling based on factor analysis for the waterenergy-food nexus conundrum," The Science of the Total Environment, vol. 651, pp. 309-322, 2018.

[37] S. Sarabi, Q. Han, A. G. L. Romme, B. D. Vries, R. Valkenburg, and E. D. Ouden, "Uptake and implementation of naturebased solutions: an analysis of barriers using interpretive structural modeling," Journal of Environmental Management, vol. 270, Article ID 110749, 2020.

[38] H. Shimizu, T. Tanikawa, H. Mizuguchi, Y. Tani, and K. Ogasawara, "Analysis of factors inhibiting the dissemination of telemedicine in Japan: using the interpretive structural modeling," Telemedicine and e-Health, vol. 27, no. 5, pp. 575-582, 2020.

[39] G. Cuaya, A. M. Muñoz, L. C. Nuñez et al., "A dynamic Bayesian network for estimating the risk of falls from real gait data," Medical, \& Biological Engineering \& Computing, vol. 51, no. 1-2, pp. 29-37, 2013.

[40] X. Wu, H. Liu, L. Zhang, M. J. Skibniewski, Q. Deng, and J. Teng, "A dynamic Bayesian network based approach to safety decision support in tunnel construction," Reliability Engineering \& System Safety, vol. 134, pp. 157-168, 2015.

[41] F. Zhou, "Fuzzy analytic hierarchy process for risk evaluation of collapse during construction of mountain tunnel," Journal of Central South University, (in Chinese), 2008.

[42] N. Sucheta and P. S. Prakash, "A causal mapping approach to constructing Bayesian networks," Decision Support Systems, vol. 38, no. 2, pp. 259-281, 2004.

[43] Y. E. Senol, Y. V. Aydogdu, B. Sahin, and I. Kilic, "Fault Tree Analysis of chemical cargo contamination by using fuzzy approach," Expert Systems with Applications, vol. 42, no. 12, pp. 5232-5244, 2015.

[44] D. F Li, Fuzzy Multiobjective Many-Person Decision Makings and Games, , National Defence IndustryPress, Beijing China, 2003pp. 45-47, (in Chinese). 